\title{
Estimativa de capacidades de combinação em gerações iniciais de seleção de batata
}

\author{
Giovani $O$ da Silva ${ }^{1}$; Arione da $\mathrm{S}$ Pereira ${ }^{2}$; Velci Q de Souza $^{3}$; Fernando Irajá $\mathbf{F}$ de Carvalho ${ }^{3}$; Roberto \\ Fritsche Neto ${ }^{3}$ \\ ${ }^{1}$ Embrapa Hortaliças, C. Postal 218, 70359-970 Brasília-DF; 2 ${ }^{2}$ mbrapa Clima Temperado, C. Postal 403, 96001-970 Pelotas-RS; ${ }^{3}$ UFPel, \\ C. Postal 354, 96010-900 Pelotas-RS; olegario@cnph.embrapa.br; arione@cpact.embrapa.br; velciq@gmail.com; carvalho@ufpel.tche. \\ br; rfneto@hotmail.com
}

\section{RESUMO}

Verificou-se as estimativas das capacidades de combinação de genitores de batata em gerações iniciais de seleção. Os experimentos foram realizados na Embrapa Clima Temperado, Pelotas (RS). Foram avaliadas 20 famílias derivadas de nove genitores cruzados em esquema parcial 4 x 5 (C-1750-15-95; 2CRI-1149-1-78; C-17866-96 e 'Eliza'; 'White Lady'; 'Asterix'; 'BP-1'; 'Vivaldi' e 'Ágria'). As famílias foram avaliadas na geração de plântula e na primeira geração de campo, utilizando o delineamento experimental de blocos com tratamentos ao acaso, com três repetições. A parcela consistiu de uma amostra de 15 genótipos de uma família. Nas duas gerações foram avaliados os caracteres rendimento, número e massa média de tubérculo. Os dados foram submetidos às análises de variância conjunta e dialélica parcial. Para rendimento verificou-se efeito gênico predominantemente aditivo, enquanto para número e massa média de tubérculo constatou-se tanto efeito aditivo e não aditivo, igualmente importantes. 2CRI-1149-1-78 e 'White Lady' revelaram-se os genitores mais promissores para os três caracteres, enquanto 'Ágria' destacou-se para massa média. As gerações expressaram estimativas similares de capacidade geral de combinação.

Palavras-chave: Solanum tuberosum L., fatorial, gerações precoces, dialelo parcial.

\begin{abstract}
Estimation of the combining ability in early generations of potato selection

The combining ability of potato genotypes was estimated in early generations of selection. The experiments were carried out at Embrapa Clima Temperado, in Pelotas, Brazil. Twenty potato families derived from nine genotypes crossed in a $4 \times 5$ partial mating design (C-1750-15-95, 2CRI-1149-1-78, C-1786-6-96 and 'Eliza'; 'White Lady', 'Asterix', 'BP-1', 'Vivaldi' and 'Ágria') were evaluated. The families were evaluated in seedling and first field generation, in a randomized complete block design, with three replications of 15 genotypes. Each plot consisted of a sample of 15 genotypes of a family. In the two generations, yield, number and average tuber weight were evaluated. The data were submitted to analysis of variance and to partial diallel analysis. For yield, the gene additive effects predominated, while for tuber number and average tuber mass, both additive and non additive effects were equally important. 2CRI-11491-78 and 'White Lady' showed to be the most promising parents for the three traits, while 'Ágria' revealed superiority for mean tuber weight. The two generations presented similar estimative of general combining ability.
\end{abstract}

Keywords: Solanum tuberosum L., factorial mating design, early generations, partial diallel.

(Recebido para publicação em 27 de agosto de 2008; aceito em 11 de agosto de 2009) (Received in August 27, 2008; accepted in August 11, 2009)

\begin{abstract}
$\mathrm{A}^{\mathrm{a}}$ alta heterozigosidade e a herança tetraplóide da batata Solanum tuberosum dificultam a aplicação de vários modelos biométricos (Gopal, 1998), devido a teoria genético-biométrica pressupor que a herança é dissômica e que a população das quais os pais são amostrados está em equilíbrio panmítico ou consiste de linhagens endogâmicas (Barbosa \& Pinto, 1998).

Para a seleção de genitores, uma das metodologias mais eficientes e comumente utilizadas em programas de melhoramento genético é a análise dialélica, a qual propicia estimativas de
\end{abstract}

parâmetros úteis na seleção de genitores para hibridação e no entendimento da ação gênica envolvidos na determinação dos caracteres e da existência de heterose (Cruz et al., 2004), proporcionando assim grandes avanços para a seleção (Jaramillo et al., 2005). Existem vários métodos para a análise de cruzamentos dialélicos, sendo que o proposto por Griffing (1956) é amplamente empregado. Esse método proporciona informações a respeito da capacidade geral de combinação dos genitores (CGC), que está relacionada com a concentração de genes predominantemente aditivos, e da capacidade específica de combinação (CEC) relacionada com a concentração de genes de efeito basicamente não aditivo (dominância e epistasia) (Castiglioni et al., 1999).

A dificuldade do estudo de um número grande de genitores no sistema completo fez com que adaptações como os dialelos parciais, fossem desenvolvidas. Os dialelos parciais envolvem a avaliação de genitores dispostos em dois grupos, pertencentes ou não a um conjunto comum, sendo as inferências feitas para cada grupo (Cruz et al., 2004).

Quanto à utilização dos caracteres 
rendimento, massa média e número de tubérculos, Silva (2006) verificou, por meio da condução de dois experimentos em casa de vegetação, que para estes caracteres é possível obter ganhos genéticos com a seleção ainda na geração de plântula. Silva et al. (2008) verificaram que pode-se fazer seleção correlacionada na geração de plântula para alguns caracteres, sendo uma boa opção quando favorece caracteres com menores herdabilidades. Sendo possível obter ganhos para aparência de tubérculo e formato de tubérculo selecionando curvatura de tubérculo; seleção em achatamento de tubérculo para favorecer uma menor curvatura de tubérculo e vice versa; e para maior tamanho de tubérculo selecionando massa média de tubérculo, rendimento de tubérculo e número de tubérculos.

As informações disponíveis, no que se refere à utilização de análise dialélica em batata e, principalmente, para os caracteres estudados no presente trabalho, é limitada a poucos trabalhos, provavelmente devido à dificuldade de formação de combinações entre vários genitores no formato de uma análise dialélica pois, dependendo da combinação, a obtenção de frutos é difícil enquanto para outros a compatibilidade é maior.

O objetivo do presente trabalho foi estimar as capacidades de combinação de genitores e híbridos de batata em gerações iniciais de seleção, com intento de obter conhecimentos mais amplos sobre a eficiência da seleção em gerações precoces.

\section{MATERIAL E MÉTODOS}

Os experimentos foram realizados na Embrapa Clima Temperado, em Pelotas (RS) $\left(31^{\circ} \mathrm{S}, 52^{\circ} \mathrm{W}\right)$. Foram avaliadas famílias híbridas de batata originadas a partir de cruzamentos controlados entre nove genitores de batata escolhidos ao acaso em modelo parcial de dois grupos de genitores $(4 \times 5)$, com o modelo do "experimento 2" de Comstock \& Robinson (1948), que envolvem a avaliação de genitores dispostos em dois grupos, pertencentes ou não a um conjunto comum, segundo Cruz et al. (2004). Os cruzamentos proporcionaram vinte famílias para avaliação. Os quatro geni- tores do primeiro grupo foram C-175015-95, 2CRI-1149-1-78, C-1786-6-96 e 'Eliza'; e os cinco genitores do segundo grupo foram as cultivares 'White Lady', 'Asterix', 'BP-1', 'Vivaldi' e 'Ágria'.

Na primavera de 2004, foi produzida a primeira geração (geração de plântula) em casa de vegetação, sendo as sementes botânicas germinadas em sementeiras e as plântulas transplantadas para sacos plásticos, contendo dois litros de substrato, para produção de minitubérculos. As plântulas foram distribuídas em blocos ao acaso com três repetições. Cada parcela foi composta de uma amostra de 15 plântulas escolhidas aleatoriamente para representar cada cruzamento. $\mathrm{O}$ espaçamento entre plantas e entre linhas foi de $0,10 \mathrm{~m}$. As plântulas foram mantidas nessas condições até a colheita, que ocorreu aos 77 dias, quando os tubérculos foram transportados para instalações apropria- das para serem efetuadas as avaliações. Após as avaliações, os tubérculos foram armazenados em câmara fria a $4^{\circ} \mathrm{C}$.

Na primavera de 2005 foi produzida a segunda geração (primeira geração clonal). Um tubérculo de tamanho médio de cada genótipo e padronizado para todas as plântulas, foi plantado a campo, utilizando o mesmo delineamento experimental de 2004. Após a maturação, as plantas foram colhidas separadamente e realizadas as avaliações nos tubérculos.

Foram avaliados em ambas as gerações: rendimento de tubérculos ( $\mathrm{g}$ / planta); número de tubérculos por planta e massa média de tubérculos $(\mathrm{g})$.

Os dados foram transformados por $(\sqrt{ } X+0,5)$ para corrigir o efeito de normalidade (Lilliefors) (Campos, 1983) e foram submetidos à análise de homogeneidade de variância (teste de Bartllet) (Steel \& Torrie, 1980).

Tabela 1. Estimativas das capacidades gerais de combinação (CGC) para os genitores de batata dos grupos 1 e 2, utilizados em esquema de cruzamento dialélico parcial (estimation of the general capacities of combination (CGC) for the potato genitors of the groups 1 and 2, used in partial diallel outline of crossing). Pelotas, UFPel, 2007.

\begin{tabular}{|c|c|c|c|}
\hline & \multicolumn{3}{|c|}{ CGC grupo $1 \mathrm{x}$ ano 1} \\
\hline & NTU* & REN* (g/planta) & МAM* (g) \\
\hline C-1750-15-95 & $-0,03$ & $-0,08$ & $-0,03$ \\
\hline 2CRI-1149-1-78 & 0,09 & 0,47 & 0,15 \\
\hline C-1786-6-96 & 0,07 & $-0,06$ & $-0,16$ \\
\hline \multirow[t]{3}{*}{ 'Eliza' } & $-0,13$ & $-0,32$ & 0,04 \\
\hline & \multicolumn{3}{|c|}{ CGC grupo $1 \mathrm{x}$ ano 2} \\
\hline & NTU* & REN* (g/planta) & МАM* (g) \\
\hline C-1750-15-95 & 0,07 & $-0,60$ & $-0,34$ \\
\hline 2CRI-1149-1-78 & 0,02 & 0,20 & $-0,10$ \\
\hline C-1786-6-96 & $-0,35$ & $-0,80$ & 0,46 \\
\hline \multirow[t]{3}{*}{ Eliza } & 0,26 & 1,20 & $-0,02$ \\
\hline & \multicolumn{3}{|c|}{ CGC grupo $2 x$ ano 1} \\
\hline & NTU* & REN* (g/planta) & MAM* (g) \\
\hline White Lady & $-0,01$ & 0,41 & $-0,07$ \\
\hline Asterix & $-0,04$ & $-0,40$ & $-0,16$ \\
\hline BP-1 & 0,06 & $-0,38$ & $-0,14$ \\
\hline Vivaldi & 0,10 & 0,12 & 0,10 \\
\hline \multirow[t]{3}{*}{ Ágria } & $-0,11$ & 0,25 & 0,27 \\
\hline & \multicolumn{3}{|c|}{ CGC grupo $2 x$ ano 2} \\
\hline & NTU* & REN* (g/planta) & MAM* (g) \\
\hline White Lady & 0,22 & 1,06 & $-0,12$ \\
\hline Asterix & 0,02 & $-0,93$ & $-0,30$ \\
\hline BP-1 & 0,13 & $-0,04$ & $-0,31$ \\
\hline Vivaldi & 0,002 & 0,30 & 0,06 \\
\hline Ágria & $-0,37$ & $-0,40$ & 0,68 \\
\hline
\end{tabular}

*Significativo a 5\% de probabilidade de erro pelo teste F; NTU= número de tubérculos; $\mathrm{REN}=$ rendimento de tubérculos; MAM= massa média de tubérculos $(*$ significant at $5 \%$ of error probability by test $\mathrm{F}$; $\mathrm{NTU}=$ tuber number; $\mathrm{REN}=$ tuber yield; $\mathrm{MAM}=$ tuber medium mass). 
Tabela 2. Capacidades específicas de combinação (CEC) estimadas para dois anos de cultivo em 20 híbridos de batata (specific capacities of combination (CEC) estimated in two years of cultivation for 20 potato hybrids). Pelotas, UFPel, 2007.

\begin{tabular}{|c|c|c|c|c|}
\hline \multicolumn{2}{|c|}{ Cruzamento } & \multicolumn{3}{|c|}{ CEC $x$ ano 1} \\
\hline Grupo 1 & Grupo 2 & NTU* & REN (g/planta) & MAM* (g) \\
\hline C-1750-15-95 & White Lady & $-0,23$ & $-1,52$ & $-0,33$ \\
\hline C-1750-15-95 & Asterix & $-0,06$ & 0,07 & $-0,13$ \\
\hline C-1750-15-95 & BP-1 & 0,04 & $-0,06$ & $-0,03$ \\
\hline C-1750-15-95 & Vivaldi & 0,05 & 0,38 & 0,28 \\
\hline C-1750-15-95 & Ágria & 0,18 & 1,14 & 0,24 \\
\hline 2CRI-1149-1-78 & White Lady & 0,22 & 0,42 & $-0,16$ \\
\hline 2CRI-1149-1-78 & Asterix & $-0,15$ & 0,12 & 0,45 \\
\hline 2CRI-1149-1-78 & BP-1 & $-0,06$ & $-0,10$ & $-0,14$ \\
\hline 2CRI-1149-1-78 & Vivaldi & 0,26 & $-0,03$ & $-0,47$ \\
\hline 2CRI-1149-1-78 & Ágria & $-0,26$ & $-0,41$ & 0,34 \\
\hline C-1786-6-96 & White Lady & $-0,03$ & 0,20 & 0,18 \\
\hline C-1786-6-96 & Asterix & 0,00 & 0,53 & 0,26 \\
\hline C-1786-6-96 & BP-1 & $-0,07$ & $-0,12$ & 0,23 \\
\hline C-1786-6-96 & Vivaldi & 0,07 & $-0,14$ & $-0,25$ \\
\hline C-1786-6-96 & Ágria & 0,06 & $-0,47$ & $-0,30$ \\
\hline Eliza & White Lady & 0,05 & 0,91 & 0,33 \\
\hline Eliza & Asterix & 0,10 & $-0,72$ & $-0,58$ \\
\hline Eliza & BP-1 & 0,11 & 0,28 & $-0,03$ \\
\hline Eliza & Vivaldi & $-0,27$ & $-0,22$ & 0,46 \\
\hline Eliza & Ágria & $-0,01$ & $-0,26$ & $-0,17$ \\
\hline \multicolumn{2}{|c|}{ Cruzamento } & \multicolumn{3}{|c|}{ CEC $x$ ano $2++$} \\
\hline Grupo 1 & Grupo 2 & NTU* & REN (g/planta) & MAM (g) \\
\hline C-1750-15-95 & White Lady & $-0,01$ & 0,89 & 0,47 \\
\hline C-1750-15-95 & Asterix & $-0,34$ & $-0,34$ & 0,22 \\
\hline C-1750-15-95 & BP-1 & $-0,14$ & 0,41 & 0,36 \\
\hline C-1750-15-95 & Vivaldi & 0,26 & 0,31 & $-0,36$ \\
\hline C-1750-15-95 & Ágria & 0,23 & $-1,26$ & $-0,70$ \\
\hline 2CRI-1149-1-78 & White Lady & 0,18 & $-1,63$ & $-0,11$ \\
\hline 2CRI-1149-1-78 & Asterix & 0,05 & 0,74 & 0,00 \\
\hline 2CRI-1149-1-78 & BP-1 & $-0,05$ & $-0,25$ & 0,04 \\
\hline 2CRI-1149-1-78 & Vivaldi & 0,02 & $-0,35$ & $-0,16$ \\
\hline 2CRI-1149-1-78 & Ágria & $-0,20$ & $-1,49$ & 0,24 \\
\hline C-1786-6-96 & White Lady & 0,11 & 0,28 & $-0,18$ \\
\hline C-1786-6-96 & Asterix & $-0,05$ & $-0,82$ & $-0,15$ \\
\hline C-1786-6-96 & BP-1 & $-0,02$ & $-0,07$ & $-0,23$ \\
\hline C-1786-6-96 & Vivaldi & $-0,05$ & 0,19 & 0,31 \\
\hline C-1786-6-96 & Ágria & 0,02 & 0,42 & 0,25 \\
\hline Eliza & White Lady & 0,09 & 0,47 & $-0,18$ \\
\hline Eliza & Asterix & 0,34 & 0,43 & $-0,08$ \\
\hline Eliza & BP-1 & 0,21 & $-0,09$ & $-0,16$ \\
\hline Eliza & Vivaldi & 0,19 & $-0,15$ & 0,21 \\
\hline Eliza & Ágria & $-0,45$ & $-0,65$ & 0,21 \\
\hline
\end{tabular}

*Significativo a $5 \%$ de probabilidade de erro pelo teste F; NTU= número de tubérculos; $\mathrm{REN}=$ rendimento de tubérculos; MAM = massa média de tubérculos $(*$ significant at $5 \%$ of error probability by test F; NTU= tuber number; REN= tuber yield; MAM= tuber medium mass).
Posteriormente, foram utilizados para análise de variância conjunta e análise dialélica parcial conjunta e, para cada ano, devido a interações de capacidades de combinação $\mathrm{x}$ ano. Foram considerandos efeitos fixos para geração e para genótipos, com utilização do programa GENES (Cruz, 2006).

\section{RESULTADOS E DISCUSSÃO}

Foram avaliadas apenas as famílias, devido aos genitores apresentarem tubérculos maiores e, portanto, não poderem ser comparados com gerações iniciais de seleção. Segundo Tai \& Young (1991) para se fazer boas inferências não necessariamente deve-se incluir os genitores.

Para todos os caracteres houve significância dos efeitos de cruzamentos e da interação cruzamento e ano (Tabela 1). Desta forma, as discussões foram feitas para cada ano. Os coeficientes de variação experimental, que são um indicativo da precisão experimental, foram reduzidos para todos os caracteres, variando de 7,30 a 9,16\%, indicando que os resultados das avaliações são confiáveis.

Com exceção de rendimento de tubérculos nos dois anos e de massa média de tubérculo no segundo ano, para os demais caracteres houve significância de efeitos de capacidade geral (CGC) e específica de combinação (CEC). Isso indica que para rendimento de tubérculos, uma vez que somente a CGC foi significativa (Tabelas 1 e 2), há predominância de efeitos aditivos no controle genético do caráter, e que o desempenho da progênie pode ser previsto sem a realização dos cruzamentos e avaliação dos híbridos (Barbosa \& Pinto, 1998).

Os resultados obtidos são discordantes dos obtidos por Barbosa \& Pinto (1998), Bradshaw et al. (2000) e Mullin $\&$ Lauer (1966) que verificaram significância de CEC e CGC para rendimento de tubérculos; bem como de Killick (1977), que constatou apenas CEC significativa para rendimento de tubérculos, número de tubérculos e massa média de tubérculos, além de Plaisted et al. (1962), que para rendimento de tubérculos, também obtiveram estimativas 
Tabela 3. Estimativas das médias das combinações dos genitores para os caracteres rendimento ( $\mathrm{g} /$ planta), massa média $(\mathrm{g})$ e número de tubérculos para o primeiro e segundo ano de cultivo (estimation of the means of genitors combinations for the characters yield ( $\mathrm{g} /$ plant), medium mass ( $\mathrm{g}$ ) and tuber number for the first and second year of cultivation). Pelotas, UFPel, 2007.

\begin{tabular}{|c|c|c|c|c|c|c|c|}
\hline \multicolumn{2}{|c|}{ Cruzamento } & \multicolumn{3}{|c|}{$\begin{array}{c}\text { Média do primeiro } \\
\text { ano }\end{array}$} & \multicolumn{3}{|c|}{$\begin{array}{l}\text { Média do segundo } \\
\text { ano }\end{array}$} \\
\hline Grupo 1 & Grupo 2 & NTU & REN & МАМ & NTU & REN & МАМ \\
\hline$-1750-15-95$ & White Lady & 4,07 & 48,12 & 12,01 & 5,61 & 523,91 & 37,91 \\
\hline$-1750-15-95$ & & 5,29 & 71,37 & & 11,59 & 382,89 & 32,76 \\
\hline$-1750-15-95$ & BP-1 & 5,69 & 83,44 & 16,31 & 13,81 & 449,85 & 34,32 \\
\hline$-1750-15-95$ & & 5,56 & & & & 460,23 & 30,28 \\
\hline$-1750-15-95$ & Agria & 5,55 & 103,57 & 20,09 & 12,87 & 364,32 & 33,45 \\
\hline 2CRI-1149-1-78 & White Lady & 6,87 & 88,48 & 14,57 & 13,86 & 445,09 & 33,73 \\
\hline 2CRI-1149-1-78 & Asterix & 4,78 & 81,67 & 22,69 & 14,07 & 456,87 & 32,96 \\
\hline 2CRI-1149-1-78 & BP-1 & 5,82 & 92,65 & 16,93 & 14,11 & 453,02 & 33,26 \\
\hline 2CRI-1149-1-78 & Vivaldi & 7,82 & 88,46 & 12,39 & 13,38 & 463,64 & 35,22 \\
\hline 2CRI-1149-1-78 & Agria & 4,04 & 83,77 & 20,71 & 12,31 & 509,40 & 48,54 \\
\hline C-1786-6-96 & White Lady & 5,43 & 74,42 & 14,90 & 13,26 & 487,40 & 39,74 \\
\hline$-1786-6-96$ & Asterix & 5,47 & 79,08 & 16,25 & 10,70 & 356,83 & 37,81 \\
\hline & & 5,55 & 81,96 & & 11,69 & 421,73 & 36,74 \\
\hline C-1786-6-96 & Vivaldi & 6,69 & 76,45 & 11,70 & 10,61 & 446,82 & 48,66 \\
\hline C-1786-6-96 & & 5,46 & 72,89 & & 8,66 & 423,20 & 56,87 \\
\hline Eliza & White Lady & 4,93 & 82,92 & 17,72 & 18,00 & 594,22 & 33,96 \\
\hline Eliza & Asterix & 4,98 & 54,68 & 11,49 & 18,43 & 494,95 & 33,00 \\
\hline & BP-1 & 5,53 & 84,86 & 16,90 & 18,29 & 511,84 & 31,99 \\
\hline Eliza & Vivaldi & 4,04 & 70,82 & 23,08 & 13,90 & 524,28 & 40,86 \\
\hline Eliza & Ágria & 4,34 & 72,48 & 17,18 & 9,63 & 467,13 & 49,19 \\
\hline
\end{tabular}

$\mathrm{NTU}=$ número de tubérculos; $\mathrm{REN}=$ rendimento de tubérculos; $\mathrm{MAM}=$ massa média de tubérculos $(\mathrm{NTU}=$ tuber number; $\mathrm{RE}=$ tuber yield; $\mathrm{MAM}=$ tuber medium mass $)$.

significativas apenas de CEC. Porém, são concordantes com algumas estimativas de Barbosa \& Pinto (1998) que obtiveram CEC e CGC significativas para número de tubérculos e massa média de tubérculos, e com Maris (1989) que detectou estimativa de CGC significativa para rendimento de tubérculos; no entanto este autor obteve também apenas CGC para massa média de tubérculos e número de tubérculos.

Neste estudo, não foi verificada a predominância de CGC ou CEC significativas para os diferentes caracteres. Gopal (1998) verificou predominância de CEC significativas. Da mesma forma, Killick (1977) citou vários autores, com diferentes resultados em relação à predominâncias de CGC ou CEC. Assim, pode-se conceber que a importância da CGC ou CEC depende da população e dos caracteres considerados nos estudos. Na concepção de Maris (1989), depende também do desenho experimental e/ou das condições ambientais. No presente estudo, verificou-se que as capacidades de combinação revelaram interação significativa com o ano de cultivo, devendo, pois, serem analisadas em separado para cada ano.

Em relação às estimativas de CGC significativas dos genitores do grupo 1 , C-1750-15-95 e 2CRI-1149-1-78, concluiu-se que houveram comportamentos diferenciados, C-1750-15-95 foi um dos genitores de pior comportamento, com menores estimativas de CGC; como evidenciado para número de tubérculos no primeiro ano e para rendimento de tubérculos e massa média de tubérculos no segundo. 2CRI-1149-1-78 foi o melhor, com maior CGC para rendimento de tubérculos e massa média de tubérculos no primeiro ano, e uma das maiores CGC para rendimento no segundo ano (Tabela 1). 'Eliza' foi um dos melhores genitores do grupo 1 para o segundo ano, no que se refere às estimativas de CGC, demonstrando ser um genitor promissor para número de tubérculos e para rendimento de tubérculos.

C-1786-6-96 revelou-se um genitor indesejável, em decorrência das menores estimativas para CGC quanto a rendimento de tubérculos no primeiro ano, bem como para número de tubérculos e rendimento de tubérculos no segundo ano. Para massa média de tubérculos, o clone C-1786-6-96 não demonstrou desempenho semelhante nos dois anos (Tabela 1).

Em relação às CGC do grupo 2 , 'White Lady' expressou o melhor desempenho para rendimento de tubérculos nos dois anos avaliados. No entanto, 'Asterix' foi um dos genitores de pior desempenho, sendo responsável por transferir características indesejáveis em relação a rendimento de tubérculos e para massa média de tubérculos (Tabela 1).

'BP-1' foi um dos genitores com menores CGC para massa média; no entanto, foi o mais promissor para número de tubérculos no segundo ano. 'Vivaldi' mostrou-se neutro, não contribuindo para complementações alélicas favoráveis ou não. Porém, 'Ágria' foi o melhor genitor para massa média de tubérculos, mas o pior para número de tubérculos. Este comportamento em relação à massa média de tubérculos e número de tubérculos já foi relatado. Nesse aspecto há concordância com os resultados de Maris (1988), Rodrigues \& Pereira (2003) e Gaur \& Kishore (1978), que verificaram a diminuição da massa média de tubérculos com o aumento do número de tubérculos. Esta é uma relação muito importante devido à influência na quantidade de tubérculos comerciais produzidos.

A respeito das CEC, para número de tubérculos, o cruzamento 2CRI-1149-178 x 'Vivaldi' no primeiro ano e 'Eliza' $\mathrm{x}$ 'Asterix', no segundo ano, foram as que se sobressaíram, o que pode ser confirmado pelas médias superiores expressas (Tabela 3). No entanto, como simplesmente a significância da CEC não basta para poder recomendar estes cruzamentos, devendo existir ainda, pelo menos um dos genitores com elevada CGC (Cruz et al., 2004); na primeira combinação ambos genitores contiveram CGC positivas, e para a segunda combinação, 'Eliza' revelou elevada 
CGC, o que favorece a recomendação dos pares 1149-1-78 x 'Vivaldi' e 'Eliza' x 'Asterix'.

Para massa média de tubérculos a CEC foi significativa apenas para o primeiro ano de cultivo. 'Eliza' $\mathrm{x}$ 'Vivaldi' foi a melhor combinação $(0,46)$; porém, estes genitores não expressaram elevada CGC, denotando predominância de efeitos gênicos não aditivos, não sendo possível indicar este cruzamento para a geração de famílias com características desejáveis em relação a massa média de tubérculos. A segunda melhor combinação foi 2CRI-1149-1-78 x 'Asterix' (0,45), com 2CRI-1149-1-78, que expressou elevada CGC para maior massa média de tubérculos, constituindo-se na melhor opção de híbrido para este caráter.

Concluiu-se que rendimento de tubérculos é um caráter expresso por efeito gênico predominantemente de aditividade. Para número de tubérculos e massa média de tubérculos, ambos efeitos aditivos e não aditivos são importantes. O clone 2CRI-1149-1-78, e a cultivar 'White Lady' são promissores para rendimento de tubérculos; o contrário para C-1750-15-95, C-1786-6-96 e 'Asterix'. 'Ágria' revelou-se interessante para massa média de tubérculos, porém não para número de tubérculos, enquanto 'Vivaldi' contribuiu para a geração de famílias com complementações alélicas favoráveis ou não.

\section{AGRADECIMENTOS}

Os autores agradecem à equipe de apoio do Melhoramento Genético da Batata e; aos colegas e professores do Departamento de Fitomelhoramento da Faculdade de Agronomia 'Eliseu Maciel'; e à CAPES pela bolsa concedida.

\section{REFERÊNCIAS}

BARBOSA MHP; PINTO CABP. 1998. Análise dialélica parcial entre cultivares de batata nacionais e introduzidas. Pesquisa Agropecuária Brasileira 33: 307-320.

BRADSHAW JE; TODD D; WILSON RN. 2000. Use of progeny tests for genetical studies as part of a potato (Solanum tuberosum subsp. tuberosum) breeding programme. Theoretical Applied Genetics 100: 772-781.

CAMPOS H. 1983. Estatistica experimental não-paramétrica. 4. ed. Piracicaba: FEALQ. $349 \mathrm{p}$.

CASTIGLIONI VBR; OLIVEIRA MF; ARIAS CAA. 1999. Análise da capacidade combinatória entre linhagens de girassol. Pesquisa Agropecuária Brasileira 34: 981988.

COMSTOCK RE; ROBINSON HF. 1948. The components of genetic variance in populations. Biometrics 4: 254-266.

CRUZ CD. 2006. Programa Genes: biometria: UFV. 382p.

CRUZ CD; REGAZZI AJ; CARNEIRO PC. 2004. Métodos biométricos aplicados ao melhoramento genético. Viçosa: UFV. 480p.

GAUR PC; GOPAL J; RANA MS. 1983. Combining ability for yield, its components and tuber dry matter in potato. Indian Journal of Agriculture and Science 53: 876-879.

GAUR PC; KISHORE H. 1978. Studies on character association in potatoes. The Journal of Agricultural Science 90: 215-219.

GOPAL J. 1998. Identification of superior parents and crosses in potato breeding programmes. Theoretical Applied Genetics 96: 287-293.

GRIFFING B. 1956. Concept of general and specific combining ability in relation to diallel crossing systems. Australian Journal of Biological Sciences 9: 463-493.

JARAMILLO G; MORANTE N; PEREZ JC; CALLE F; CEBALLOS H; ARIAS B; BELLOTTI AC. 2005. Diallel analysis in cassava adapted to the midaltitude valleys environment. Crop Science 45: 1058-1062.

KILLICK RJ. 1977. Genetic analysis of several traits in potatoes by means of a diallell cross. Annals of Applied Biology 86: 279-289.

MARIS B. 1988. Correlations within and between characters between and within generations as a measure for the early generation selection in potato breeding. Euphytica 37: 205-209.

MARIS B. 1989. Analysis of an incomplete diallel cross among three ssp. tuberosum varieties and seven long-day adapted ssp. andigena clones of the potato (Solanum tuberosum L.). Euphytica 41: 163-182.

MULLIN R; LAUER FI. 1966. Breeding behavior of F1 and inbred potato clones. Journal of the American Society for Horticultural Science 89: 449-455.

PLAISTED RL; SANDFORD L; FEDERER WT; KEHR AE; PETERSON LC. 1962. Specific and general combining ability for yield in potatoes. American Potato Journal 39: 185-197.

RODRIGUES AFS; PEREIRA AS. 2003. Correlações inter e intragerações e herdabilidade de cor de chips, matéria seca e produção em batata. Pesquisa Agropecuária Brasileira 38: 599-604.

SILVA GO. 2006. Critérios na escolha de genitores e mecanismos de seleção para caracteres agronômicos nas primeiras gerações em batata (Solanum tuberosum L.). Pelotas: UFPEL. 85 p. (Tese doutorado).

SILVA GO; PEREIRA AS; SOUZA VQ; CARVALHO FIF; FRITSCHE NETO R. 2008. Seleção para caracteres componentes de aparência e rendimento de tubérculo. Horticultura Brasileira 26: 325-328.

STEEL RGD; TORRIE JH. 1980. Principles and procedures of statistics. $2 \mathrm{ed}$. New York: McGraw-Hill Book. 633 p.

TAI GCC; YOUNG DA. 1991. Evaluation of potato hybrids obtained from tetraploid-diploid crosses. Plant Breeding 107: 183-189. 